\title{
Diffusion Bonding of TiC Cermet to Stainless Steel Using Impulse Pressuring with Ti-Nb Interlayer
}

\section{Li Jia, Sheng Guangmin}

\author{
Chongqing University, Chongqing 400044, China
}

\begin{abstract}
Impulse pressuring diffusion bonding (IPDB) of TiC cermet to stainless steel 06Cr19Ni10 using Ti-Nb interlayer was carried out in an attempt to reduce the bonding time and to alleviate the detrimental effect of interfacial reaction products on bonding strength. Successful bonding is achieved at $890^{\circ} \mathrm{C}$ under a pulsed pressure of 2 10 MPa within a duration of only 4 12 min, which is notably shortened in comparison with conventional diffusion bonding. Microstructure characterization reveals the existence of $\sigma$ phase with a limit solubility of $\mathrm{Nb},(\beta-\mathrm{Ti}, \mathrm{Nb})$ phase, and solid solution of $\mathrm{Ni}$ in $\alpha+\beta$-Ti in the reaction zone. Maximum shear strength of $110 \mathrm{MPa}$ is obtained when the joint is bonded for $10 \mathrm{~min}$, indicating a robust metallurgical bonding is achieved. Upon shear loading, the joints fracture along the remnant $\mathrm{Ti} / \alpha+\beta$-Ti interface and extend to the interior of $\mathrm{TiC}$ cermet in a brittle cleavage manner. This technique provides a highly promising bonding method of TiC cermet and steel.
\end{abstract}

Key words: TiC cermet; diffusion bonding; impulse pressuring; $\mathrm{Ti}-\mathrm{Nb}$; microstructure

TiC cermet is a promising material ascribed to its excellent combination of desirable properties, such as light-weight, high hardness, wear resistance and stability at elevated temperature ${ }^{[1,2]}$. However, the intensive application of $\mathrm{TiC}$ cermet is restricted, primarily due to its low fracture toughness and poor workability originated from its inherent brittleness. A promising option to take advantage of the good characteristics of cermets is to combine it with metallic structure on selected regions, generally steel.

Successful joining between $\mathrm{TiC}$ cermets and steel encountered two key obstacles: one was the chemical inertness of $\mathrm{TiC}$ cermet, while the other was their mismatch of thermal expansion coefficient (CTE) which led to high residual stress ${ }^{[3-5]}$, and consequently formed mechanical weak joint. Conventional fusion welding was infeasible in the case of dissimilar materials joining of refractory TiC cermet $\left(\sim 3067{ }^{\circ} \mathrm{C}\right){ }^{[6]}$ to steel owing to their different melting points, and would result in concentration of residual stress at the joints ${ }^{[7]}$. Diffusion bonding, by contrast, has been demonstrated to be one of the most practicable methods to effective bond ceramics to steels.
Diffusion bonding appeared as a near net shape forming processing which can be used for preparation of heat resistant joint at much lower temperature than conventional connection methods ${ }^{[8,9]}$. This bonding process was even easier using multilayer soft metals when ceramics are involved. Currently, the $\mathrm{Ti}-\mathrm{Cu}-\mathrm{Ti}{ }^{[10]}$, Ti-Ni-Ti ${ }^{[11]}$ and Ti-Cu-Ni ${ }^{[12]}$ interlayer used for diffusion bonding of ceramics to metal has been investigated. $\mathrm{Ti}$ is the most attractive active element for almost all the structure ceramics $^{[13]}$. Y. Min ${ }^{[14]}$ and R. A. Marks ${ }^{[15]}$ have studied the influence of $\mathrm{Nb}-\mathrm{Cu}-\mathrm{Ni}$ and $\mathrm{Cu}-\mathrm{Nb}-\mathrm{Cu}$ interlayer on the joint properties in the ceramic-metal bonding. Soft $\mathrm{Nb}$ was a suitable candidate to buffer the residual stress in the ceramic/metal joints attributed to its lower CTE value $\left(7.2 \times 10^{-6} \mathrm{~K}^{-1}\right)$ than those of ceramics (TiC cermet: $7.4 \times 10^{-6}$ $\left.\mathrm{K}^{-1}\right)$ and steel $\left(12 \sim 13 \times 10^{-6} \mathrm{~K}^{-1}\right)^{[6,16]}$. As discussed above, an interlayer containing $\mathrm{Ti}-\mathrm{Nb}$ was required to be capable of accommodating the incompatible chemical and physical properties between $\mathrm{TiC}$ cermet and steel in present study. Additionally, element $\mathrm{Nb}$ was infinitely soluble in $\mathrm{Ti}^{[17]}$, which avoided the formation of detrimental inter-

Received date: April 25, 2016

Foundation item: National Natural Science Foundation of China (51205428); Sharing Fund of Chongqing University's Large-scale Equipment (2013063011)

Corresponding author: Sheng Guangmin, Ph. D., Professor, College of Material Science and Engineering, Chongqing University, Chongqing 400044, P. R. China, Tel: 0086 -23-65111826, E-mail: gmsheng@cqu.edu.cn 
metallic compounds (IMCs), such as $\mathrm{Cu}_{2} \mathrm{Ti}, \mathrm{NiTi}$ and $\mathrm{Ni}_{3} \mathrm{Ti}^{[10-12]}$, to a certain extent.

In spite of successful diffusion bonding achieved in above cases, it was noted that the diffusion bonding was time consuming, as 45 120 min was generally required to complete the bonding process ${ }^{[10-15]}$. In these regards, it was of great interest to shorten the bonding time by further optimize the bonding circle, for the purpose of both productive efficiency and cost saving. Auxiliary impulse pressure can offer an advantage in the process of diffusion bonding because the pressure can enhance the speed of the atomic diffusion ${ }^{[18]}$. The compressive deformation generated by impulse pressure can fill voids and refine titanium grains ${ }^{[19]}$, which produces more grain boundaries to generate additional diffusion pathways. Thus thermodynamically, all of these factors are in good shape to shorten the bonding time, and then accelerate the bonding process. Moreover, a reduction in bonding time, which can retard the excessive growth of interfacial IMCs, would in turn potentially contribute to the bonding strength.

To this end, a modified bonding technique, impulse pressuring diffusion bonding (IPDB) using Ti-Nb interlayer was intended in the current investigation, to realize robust bonding of TiC cermet to steel within a greatly reduced duration.

\section{Experiment}

The base materials, hot pressure sintered (HPS) TiC cermet and commercially 304 stainless steel (SS, 06Cr19Ni10), were processed into $3 \mathrm{~mm} \times 4 \mathrm{~mm} \times 8 \mathrm{~mm}$ and $3 \mathrm{~mm} \times 8 \mathrm{~mm} \times 30 \mathrm{~mm}$, respectively. The multilayer metals of pure $\mathrm{Ti}$ and $\mathrm{Nb}$, with a thickness of 20 and $30 \mu \mathrm{m}$ respectively, were used. The chemical composition and room temperature thermophysical properties of substrates and interlayer are given in Tables 1 and 2. The mating surfaces of the specimen were prepared by conventional grinding and polishing techniques, and subsequently cleaned in acetone to eradicate any residual contamination. Bonding trials were performed in a Gleeble-1500D tester and the parameters were: temperature $T=890^{\circ} \mathrm{C}$, pulsed compressive load $P_{\min }=2 \mathrm{MPa}$ and $P_{\max }=10 \mathrm{MPa}$, impulse frequency $f=0.5 \mathrm{~Hz}$, bonding time $t=4 \sim 12 \mathrm{~min}$, in vacuum maintained at $1 \times 10^{-3} \mathrm{~Pa}$. The assembly sequence of samples was TiC-Ti-Nb-SS.

Subsequent to bonding, selected specimens were sectioned and microstructural observations were conducted in field emission scanning electron microscope (FEI-SEM, FEI Nova400) using back scattered mode (BSE) to reveal the interfacial reaction layers. Chemical concentration profile across the joints was determined using energy dispersive spectroscope (EDS). Room temperature shear tests were performed in a testing machine (Instron 1342) at a crosshead speed of $0.025 \mathrm{~mm} / \mathrm{min}$ to examine the mechanical properties, as displayed in Fig.1. Fracture morphologies were observed by SEM and X-ray diffraction (XRD) to identify the fracture location and characteristic of the joints.

\section{Results and Discussion}

\subsection{Mechanical properties}

Shear strength of the IPDB joints with the change of bonding time and the axial shear load-displacement curve are given in Fig.2. The shear strength is determined by the formula $\sigma=F / S$ ( $\sigma$ is the strength, $\mathrm{MPa} ; F$ is the loading, $\mathrm{kN}$; and $S$ is the bonded acreage of the sample $3 \mathrm{~mm} \times 8 \mathrm{~mm}$ ). The TiC cermet/SS joint is destroyed at the maximum load and then the load decreases suddenly, shown in Fig.2b. This means that fracture of the TiC cermet-SS joint is a brittle manner.

It is well known that the most important parameters for diffusion bonding, bonding temperature, pressure and holding time, are not independent with each other. At a given temperature, the bonding time required to complete the bonding is a function of the applied pressure. A higher pressure would preferentially result in reduced time required. In the short time range of $4 \sim 6 \mathrm{~min}$, the joints exhibit a rather low strength of approximately 20 54.8 MPa. As the bonding time increases, so does the number of

Table 1 Chemical composition of substrates (wt $\%)$

\begin{tabular}{cccccccccccc}
\hline Material & $\mathrm{C}$ & $\mathrm{Ni}$ & $\mathrm{W}$ & $\mathrm{Mo}$ & $\mathrm{Ti}$ & $\mathrm{Cr}$ & $\mathrm{Mn}$ & $\mathrm{S}$ & $\mathrm{P}$ & $\mathrm{Fe}$ \\
\hline $\mathrm{TiC}$ & 19.6 & 9.54 & 2.94 & 1.40 & $\mathrm{Bal}$ & & & & & \\
$\mathrm{SS}$ & 0.12 & 8.43 & & & & 18.67 & 1.35 & 0.03 & 0.035 & Bal. \\
\hline
\end{tabular}

Table 2 Room temperature thermo-physical properties of Ti, Nb and substrates ${ }^{[6,16]}$

\begin{tabular}{cccc}
\hline Materials & $\begin{array}{c}\text { Melting } \\
\text { point/K }\end{array}$ & $\begin{array}{c}\text { Coefficient of thermal } \\
\text { expansion/ } \times 10^{-6} \mathrm{~K}^{-1}\end{array}$ & $\begin{array}{c}\text { Elasticity } \\
\text { modulus/GPa }\end{array}$ \\
\hline $\mathrm{Ti}$ & $1913 \sim 1943$ & 9.4 & 115 \\
$\mathrm{Nb}$ & 2468 & 7.2 & 105 \\
$\mathrm{TiC}$ & 3067 & 7.4 & $410 \sim 510$ \\
$\mathrm{SS}$ & $1399 \sim 1455$ & $12 \sim 13$ & 193 \\
\hline
\end{tabular}

impulses ( $f$ at $0.5 \mathrm{~Hz}$ ). When $t<10 \mathrm{~min}$, elemental diffusion gradually increases as the number of impulses multiplies. The limited macroscopic deformation of the joint can be attributed to the increasing loading cycle the substrate experienced, which further promotes the atomic diffusivity ${ }^{[19]}$. It is thus deduced that the poor bonding quality of the joints is precisely because of the insufficient mass transfer of the reaction interface in inadequately bonding time. The 

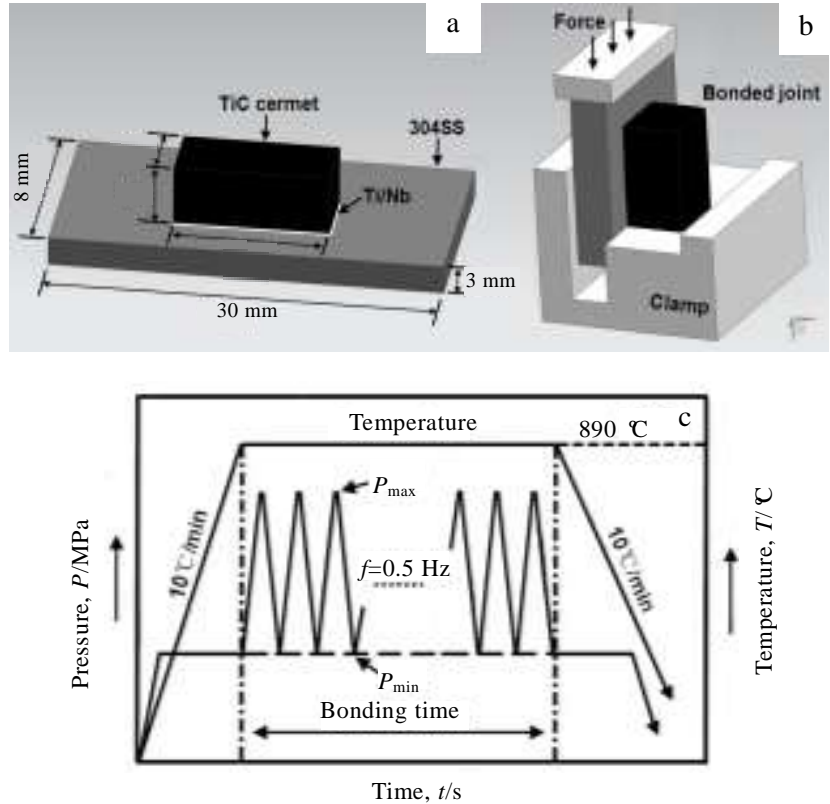

Fig. 1 Schematic diagram of assembly samples (a), shear test for bonded joints (b) and processing curve of impulse pressuring diffusion bonding (c)
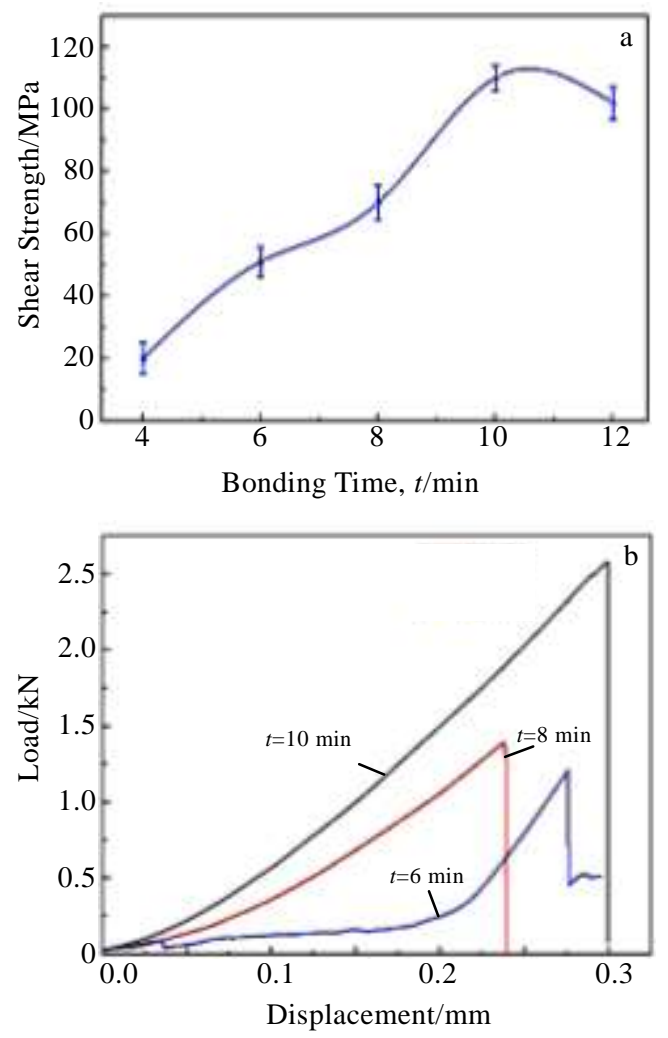

Fig. 2 Shear strength measurement (a) of the joints bonded at different time and the relationship between load and displacement (b) joint strength is notably improved to $110 \mathrm{MPa}$ when the bonding time increases to $10 \mathrm{~min}$. The improvement can be attributed to the enhanced interdiffusion at the bonding interface. Obviously, atomic diffusivity is dominant in leading to the observed change, since atomic diffusion has a decisive influence on the formation of bonded joint, thereby affecting the strength of the joint significantly. However, when $t>10 \mathrm{~min}$, the joint shear strength decreases steadily with a further increase in bonding time, which can be ascribed to the ease of deformation and thickening of the brittle phases ${ }^{[20]}$. In all cases, the excellent mechanical property of joints indicates that good metallurgical bonding is achieved with appropriate bonding parameters.

\subsection{Microstructure characterization}

Detailed microstructures of maximum strength joint bonded for 10 min studied by SEM are shown in Fig.3. The micrographs exhibit an excellent bonding along the interface of the bonded couples. A reaction and interdiffusion area is found at the TiC cermet-SS interface, and five distinct layers marked as A, B, C, D and E are observed at the interface in Fig.3a. Corresponding elemental concentration profile of this joint is obtained to identify the phase constituent of the interfacial reaction layers, as shown in Fig.3b. Fig.3c is the enlarged micrograph of layer "E" in Fig.3a.

It can be seen that the $\mathrm{SS}-\mathrm{Nb}$ interface is planar in character. There is a thin diffusion zone " $\mathrm{A}$ " rich in $\mathrm{Fe}$ and $\mathrm{Cr}$, and $\sigma$ phase was formed here ${ }^{[17]}$. The average composition (at\%) of this $\sigma$ phase is $\mathrm{Fe} \sim 66.3, \mathrm{Cr} 24.8$, $\mathrm{Ni}$ 3.7 and $\mathrm{Nb} \sim 5.2$, as shown in Table 3. Owing to the reactive nature of $\mathrm{Nb}$, metallurgical bonding can be readily formed at the SS-Nb interface via forming $\sigma$ phase with a little solubility of $\mathrm{Nb}$, as shown in Fig.3. However, since the mutual solubility of the $\mathrm{Nb}-\sigma$ phase system is limited, relatively prolonged duration is required to achieve adequate interdiffusion, which is a time dependent process across the interface.

Adjacent to the $\mathrm{SS}-\mathrm{Nb}$ interface, the elemental concentration profile reveals no other element than $\mathrm{Nb}$. Therefore, this is the remnant $\mathrm{Nb}$ layer. This $\mathrm{Nb}$ layer with low CTE value $\left(7.2 \times 10^{-6} \mathrm{~K}^{-1}\right)$ between TiC cermet and SS can be a significant player to relieve the residual stress. Close to the remnant $\mathrm{Nb}$ interlayer, a distinct layer " $\mathrm{C}$ " is observed, and there is a plateau in the corresponding elemental concentration profile of this area. EDS analysis of this layer in Table 3 reveals a composition of $\mathrm{Nb}(49.3$ at $\%)$ and $\mathrm{Ti}(50.7$ at\%). In combination with the $\mathrm{Ti}-\mathrm{Nb}$ phase diagram, this is a $(\beta-\mathrm{Ti}, \mathrm{Nb})$ solid solution layer. According to the Arrhenius relationship:

$$
D=D_{0} \exp (-Q / R T)
$$

where $D$ is the diffusion coefficient. The diffusion coefficient of $\mathrm{Ti}\left(D_{\mathrm{Ti}}=1.79 \times 10^{-12} \mathrm{~cm}^{2} \mathrm{~s}^{-1}\right)$ is greater than that of $\mathrm{Nb}\left(D_{\mathrm{Nb}}=1.19 \times 10^{-13} \mathrm{~cm}^{2} \mathrm{~s}^{-1}\right)$ at $890{ }^{\circ} \mathrm{C}$ for the $\mathrm{Nb}-\mathrm{Ti}$ 


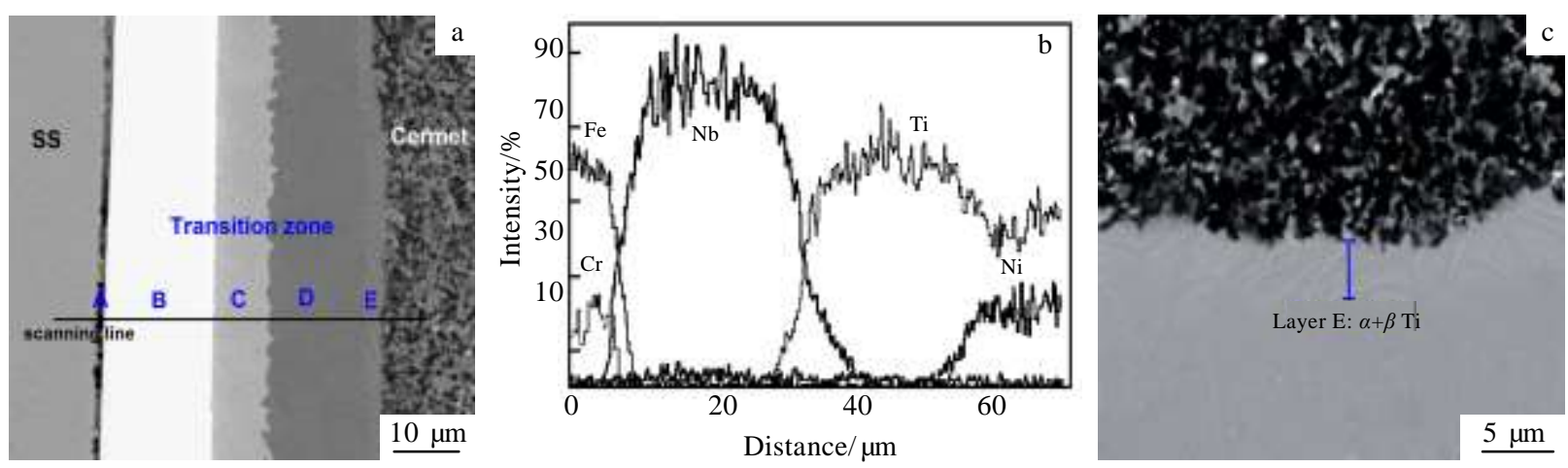

Fig. 3 SEM image of joint interface bonding for 10 min (a), elemental concentration profile (b) and enlarged micrograph of layer "E" corresponding to Fig. 3a (c)

Table 3 Chemical composition and possible phase of the marked regions in Fig.3a (at\%)

\begin{tabular}{ccccccc}
\hline Zones & $\mathrm{Fe}$ & $\mathrm{Cr}$ & $\mathrm{Nb}$ & $\mathrm{Ti}$ & $\mathrm{Ni}$ & Phases \\
\hline $\mathrm{A}$ & 66.3 & 24.8 & 5.2 & - & 3.7 & $\sigma$ \\
$\mathrm{C}$ & - & & 49.3 & 50.7 & - & $(\beta-\mathrm{Ti}, \mathrm{Nb})$ \\
$\mathrm{E}$ & - & - & 1.2 & 93.7 & 5.1 & $\alpha+\beta-\mathrm{Ti}$ \\
\hline
\end{tabular}

interface $^{[21]}$, which indicates $\mathrm{Ti}$ diffusing into $\mathrm{Nb}$ is more than $\mathrm{Nb}$ diffusing into $\mathrm{Ti}$. Therefore, the location of the $(\beta$ - Ti, Nb) would shift from the $\mathrm{Nb}$ layer to the Ti side. The $\mathrm{Nb}$ layer plays a role as effective diffusion barrier between $\mathrm{Ti}$ and SS, and the formation of Ti-Fe IMCs which have been recognized to be the most detrimental to the joint strength is successfully suppressed. After isothermal solidification and solid phase homogenization in diffusion process, partial surplus $\mathrm{Ti}$ is detected in concentration profile next to $(\beta-\mathrm{Ti}, \mathrm{Nb})$ layer.

Between the surplus Ti layer and TiC substrate, a thin light shaded layer "E" is observed with the average composition (at\%) Ti 93.7, $\mathrm{Ni} \sim 5.1$ and $\mathrm{Nb} \sim 1.2$, enlarged in Fig.3c. The concentration profiles of both $\mathrm{Ti}$ and $\mathrm{Ni}$ exhibit smooth and continuous variations. This region shows the feather-like structures of Widmanstatten $\alpha+\beta$-Ti. Due to the diffusion of $\mathrm{Ni}$, a $\beta$ stabilizing element, towards the Ti substrate, leads to the formation of $\beta$-Ti phase at bonding temperature. Therefore, during the cooling stage, Widmanstatten $\alpha+\beta$-Ti is formed because the $\beta$-Ti transforms to $\alpha+\beta$-Ti aggregate under the phase transformation point $\left(\sim 882^{\circ} \mathrm{C}\right){ }^{[22]}$. In the bonding progress, attributed to the solid state interdiffusion of elements, considerable mass transfer occurs and continuous transition layers are approached across the bonding interface.

\subsection{Analysis of fracture}

The fracture morphologies for all the TiC cermet-SS joints under the SEM micrograph, irrespective of the bonding parameters, appear alike. A typical example of maximum strength sample bonded under conditions of $T=$ $890{ }^{\circ} \mathrm{C}, P=2 \sim 10 \mathrm{MPa}, t=10 \mathrm{~min}, f=0.5 \mathrm{~Hz}$ is shown in Fig.4. The fracture surfaces as seen in Fig. 4 consist of gray matrix and relatively dark blocks of different sizes and distribution. The grains in the gray matrix magnified in Fig.4b exhibit isometric and coarse morphology but not show metallic shine, which can deduce to be TiC cermet. In contrast, extensive cleavage patterns are observed in the dark block region magnified in Fig.4c, from which it can be reasonably inferred that this region is where the shear forces are concentrated, and the joints fail in a brittle manner.

To further investigate the characterization of phases on the fracture surfaces, the existence of these constituents has also been identified by XRD of this fractured specimen, displayed in Fig.5. The XRD patterns indicate that the phases on the $\mathrm{TiC}$ cermet side are $\mathrm{Ti}$, ( $\mathrm{Ti}, \mathrm{Ni}$ ) and $\mathrm{TiC}$ (Fig.5a), while the phases found on the SS side are Ti, (Ti, $\mathrm{Ni}), \mathrm{TiC},(\beta-\mathrm{Ti}, \mathrm{Nb}), \mathrm{Nb}$ and $\gamma$-Fe (Fig.5b). In other words, $\mathrm{Ti},(\mathrm{Ti}, \mathrm{Ni})$ and $\mathrm{TiC}$ are found on both sides of the fracture. The composition of ( $\mathrm{Ti}, \mathrm{Ni})$ matches that of $\alpha+\beta$-Ti layer, and thus it can be inferred that fracture has taken place somewhere at the interface of the remnant Ti layer and $\alpha+$ $\beta$-Ti layer, and extends to the interior of $\mathrm{TiC}$ cermet. The fracture of $\mathrm{TiC}$ cermet lowers the strength of the bonded joint, indicating that this is the weak point influenced by residual stress in the impulse pressuring diffusion bonded joint.

The stresses based on the research of Zdaniewski ${ }^{[23]}$ and Blugan $^{[24]}$ revealed that the residual stresses were at maximum within the ceramics close to reaction interface, which explained the fracture extension to TiC cermet. The stresses result in crack formation at the gaps either due to the thermal expansion mismatch and subsequent differences in thermal contraction in cooling or are induced by the applied loads during indentation. Because the CTE of SS is 

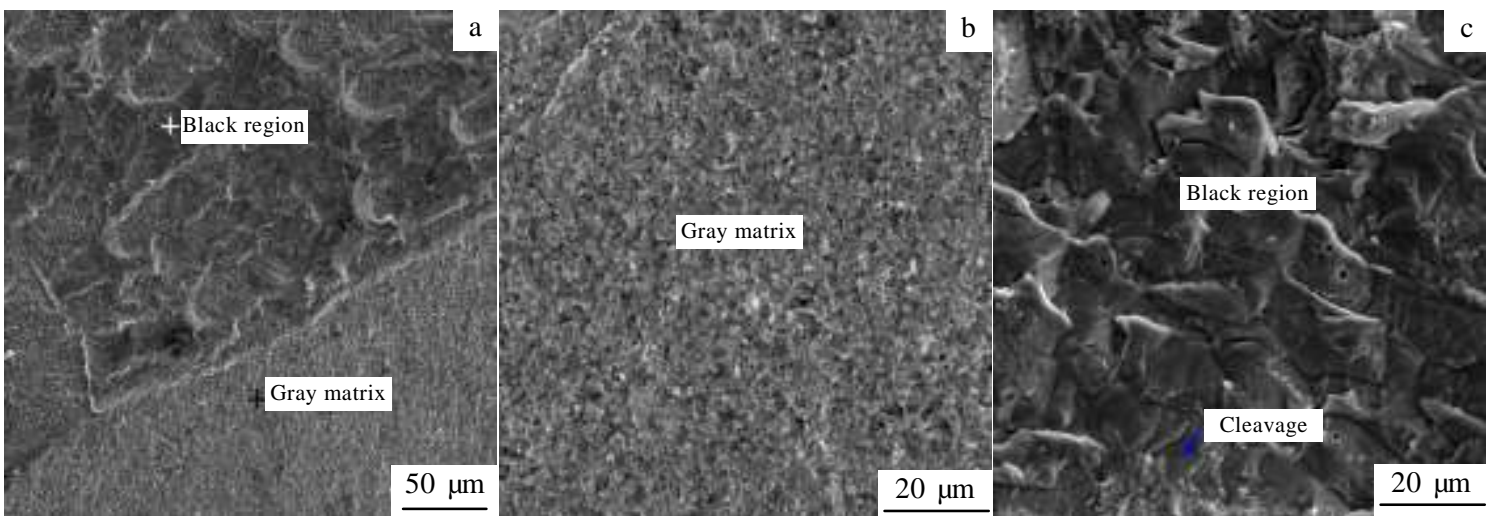

Fig. 4 Fracture surface of sample on the TiC cermet side (a), enlarged micrograph of gray matrix (b), and enlarged micrograph of black region in Fig.4a (c)
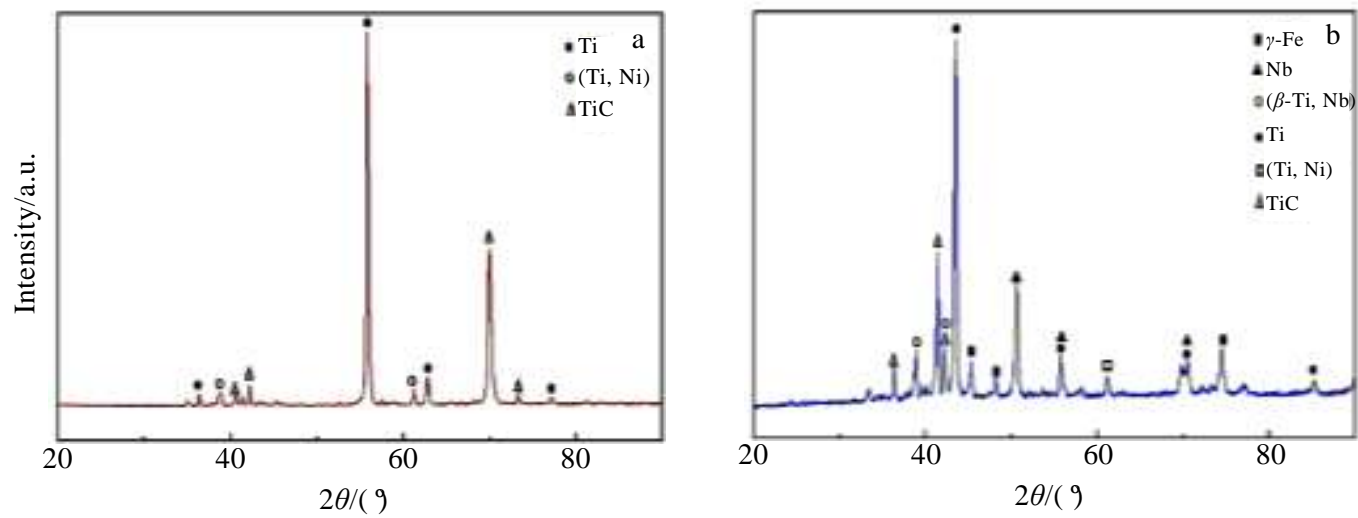

Fig. 5 XRD patterns of the fracture surface at TiC cermet side (a) and SS side (b)

higher than that of $\mathrm{TiC}$ ceramic, the tensile residual stress $\sigma_{x}$ parallel of the interface is always the largest within the joint, and in the free surface suddenly reduced to 0 . In present work, a uniaxial compressive load of $2 \sim 10 \mathrm{MPa}$ is applied along the longitudinal direction of sample in the process of bonding which results in the compressive stress $\sigma_{\mathrm{y}}$ perpendicular to the interface by lateral contraction of the ceramic and steel ${ }^{[23]}$. The addition of $\mathrm{Nb}\left(7.2 \times 10^{-6} \mathrm{~K}^{-1}\right)$ and Ti $\left(9.4 \times 10^{-6} \mathrm{~K}^{-1}\right)$ should theoretically accommodate the mismatch between TiC cermet $\left(7.4 \times 10^{-6} \mathrm{~K}^{-1}\right)$ and $\mathrm{SS}$ $\left(12 \sim 13 \times 10^{-6} \mathrm{~K}^{-1}\right)$. The CTE value of new generated $\alpha+\beta$-Ti phases adjacent to TiC cermet is $9.41 \sim 10.03 \times 10^{-6} \mathrm{~K}^{-1[6,16]}$. Thus, the residual stresses at $\mathrm{TiC}$ cermet $/ \alpha+\beta$-Ti interface are alleviated. However, there is still a weak region at $\alpha+$ $\beta$-Ti /TiC cermet interface. In fact, the fracture is not only based on the CTE values, but also determined by the plastic deformation of brazed interface ${ }^{[25]}$. The ability of plastic deformation of brazed interface is reflected by the hardness of new phases indirectly, because the low hardness corresponds to relatively high plasticity and ductility. It is obvious that the $\mathrm{TiC}$ cermet with the highest Vickers hardness $(28 \sim 35 \mathrm{GPa}){ }^{[6]}$ has low fracture toughness due to its covalent nature. This indicates that the ability of plastic deformation of $\mathrm{TiC}$ cermet is weaker than that of other metallic phases. Therefore, the fracture propagation originates from the remnant $\mathrm{Ti} / \alpha+\beta \mathrm{Ti}$ interface, and extends to the $\mathrm{TiC}$ cermet in a typical brittle fracture manner, when exerting an external shear load upon the brazed joints.

\section{Conclusions}

1) The $\mathrm{Ti}-\mathrm{Nb}$ interlayer can effectively promote the interdiffusion and reaction between TiC cermet and SS. The joints are characterized by the presence of the $\sigma$ phase with a limit solubility of $\mathrm{Nb}$, remnant $\mathrm{Nb},(\beta-\mathrm{Ti}, \mathrm{Nb})$ phase, remnant $\mathrm{Ti}$ and solid solution of $\mathrm{Ni}$ in $\alpha+\beta$-Ti, from $\mathrm{SS}$ to TiC side orderly. The detrimental IMCs are not generated in the boned joints.

2) Maximum shear strength of $110 \mathrm{MPa}$ can be achieved when the joints are bonded for $10 \mathrm{~min}$. Upon shear loading, the fracture takes place through remnant $\mathrm{Ti} / \alpha+\beta$-Ti interface to $\mathrm{TiC}$ cermet in a typical brittle fracture manner.

\section{References}

1 Miao Hezhou, Lin Xuping, Qi Longhao. Rare Metal Materials and Engineering[J], 2008, 37: 14 (in Chinese) 
2 Sun Kangning, Yin Yansheng, Li AiMing. Intermetallic Compound/Ceramic Composites[M]. Beijing: China Machine Press, 2003 (in Chinese)

3 Travessa D, Ferrante M, Ouden G D. Materials Science and Engineering $A[\mathrm{~J}], 2002,337: 287$

4 Shen X, Li Y, Putchkov U A et al. Computational Materials Science [J], 2009, 45: 407

5 Ye Dameng, Xiong Weihao. Rare Metal Materials and Engineering[J], 2008, 37(7): 1281 (in Chinese)

6 Pierson H O. Handbook of Refractory Carbides and Nitrides, 1 ed[M]. Westwood, NJ: William Andrew Publishing, 1996: 43

7 Gomez-de-Salazar J M, Barrena M I. Materials Science and Engineering $A[\mathrm{~J}], 2003,352: 162$

8 Barrena M I, de Salazar J M. Materials Letters[J], 2009, 63: 2142

9 Li Z R, Feng J C, Cao J. Materials science and technology[J], 2004, 20: 1666

10 Wang Juan, Li Yajiang, Huang Wangqun. Kovove Materials[J], 2010, 48: 227

11 Chen Z, Cao M S, Zhao Q Z. Materials Science and Engineering $A[\mathrm{~J}], 2004,380: 394$

12 Zheng C, Lou H, Fei Z et al. Journal of Materials Science Letters[J], 1997, 16: 2026

13 Wang G, Lannutti J J. Metallurgical and Materials
Transactions A[J], 1995, 26: 1499

14 Yang M, Zou Z D, Song S L et al. Key Engineering Materials[J], 2005, 297: 2435

15 Marks R A, Sugar J D, Glaeser A M. Journal of Materials Science [J], 2001, 36: 5609

16 Shackelford J F. The CRC Materials Science and Engineering Handbook[M]. Boca Raton: CRC Press Inc 2000

17 Massalski T B, Okamoto H, Subramanian P R et al. Binary Alloy Phase Diagrams CD-ROM, 2nd ed[M]. Ohio: Materials Park, ASM International, 1990

18 Han J, Sheng G M, Zhou X L et al. ISIJ International[J], 2009, 49: 86

19 Sun X J, Gu J L, Bai B Z et al. Acta Metallurgica Sinica [J], 2009, 13: 638

20 Liu G M, Zou G S, Wu A P et al. Materials Science and Engineering $A[\mathrm{~J}], 2006,415: 213$

21 Pontau A E, Lazarus D. Physical Review B[J], 1979, 19: 4027

22 Kundu S, Chatterjee S. Materials Characterization[J], 2008, 59: 631

23 Kirchner H P, Conway J C, Segall A E. Journal of the American Ceramic Society[J], 1987, 70: 104

24 Blugan G, Kuebler J, Bissig V et al. Ceramics International[J], 2007, 33: 1033

25 Singh M, Martinez Fernandez J, Asthana R et al. Ceramics International[J], 2012, 38(4): 2793

\title{
$\mathrm{Ti}-\mathrm{Nb}$ 作缓冲层的 $\mathrm{TiC}$ 金属陶瓷/不锈钢脉冲加压扩散连接
}

\author{
李 佳, 盛光敏 \\ (重庆大学, 重庆 400044)
}

\begin{abstract}
摘 要: 采用 $\mathrm{Ti}-\mathrm{Nb}$ 中间层对 $\mathrm{TiC}$ 金属陶瓷和不锈钢 $06 \mathrm{Cr} 19 \mathrm{Ni} 10$ 进行了脉冲加压扩散连接, 以实现缩短焊接时间并缓解界面产物对接头的 有害作用的目的。连接温度 $890{ }^{\circ} \mathrm{C}$, 脉冲压力 $2 ~ 10 \mathrm{MPa}$ 工艺条件下, 在4 12 min时间内即实现了陶瓷与不锈钢的有效连接, 与传统扩散 焊相比连接时间大幅缩短。对接头进行显微组织表征发现在反应界面处存在溶解了少量 $\mathrm{Nb}$ 的 $\sigma$ 相以及溶解了 $\mathrm{Ni}$ 的 $\alpha+\beta-\mathrm{Ti}$ 固溶体。在连接 时间为 $10 \mathrm{~min}$ 时得到了最大的剪切强度 $110 \mathrm{MPa}$ 。在剪切载荷下, 接头沿着剩余的 $\mathrm{Ti} / \alpha+\beta$ - $\mathrm{Ti}$ 界面扩展至陶瓷内部断裂。结果表明, 脉冲 加压扩散连接能在一定程度上缩短焊接时间, 中间层 $\mathrm{Ti} / \mathrm{Nb}$ 的合理选择能很好的抑制有害的金属间化合物的生成。
\end{abstract}

关键词: $\mathrm{TiC}$ 陶瓷; 扩散连接; 脉冲压力; $\mathrm{Ti}-\mathrm{Nb}$; 微观组织

作者简介: 李 佳, 女, 1990 年生, 博士, 重庆大学材料科学与工程学院, 重庆 400044, E-mail: 20110901001z@cqu.edu.cn 